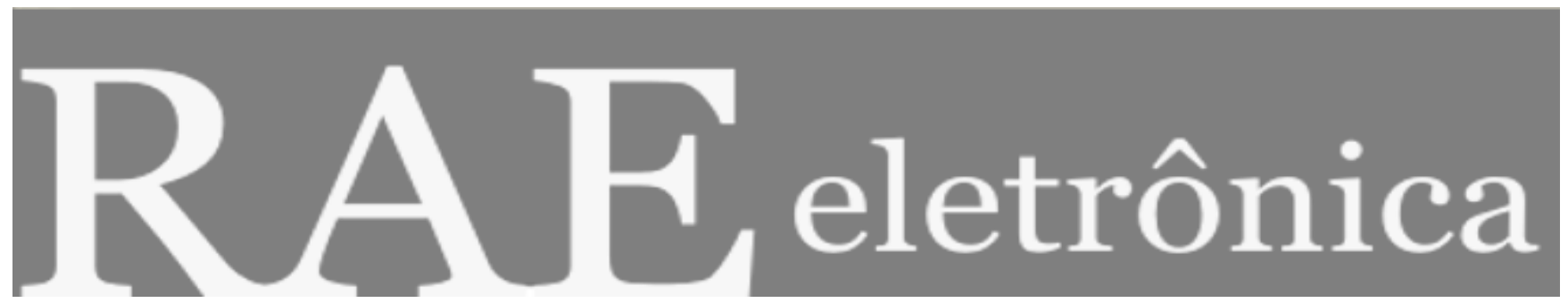

\title{
CRIAÇÃO DE INDICADORES ESTRATÉGICOS PARA O INSTITUTO DE PESQUISAS TECNOLÓGICAS DO ESTADO DE SÃO PAULO S.A - IPT
}

Por:

Edgar Bertini Ruas

RAE-eletrônica, Volume 2, Número 1, jan-jun/2003.

http://www.rae.com.br/eletronica/index.cfm?FuseAction=Artigo\&ID=1872\&Secao=2 ${ }^{\circ} \mathrm{PWC} \&$ Volume $=$ $2 \&$ Numero $=1 \&$ Ano $=2003$

CCopyright, 2002, RAE-eletrônica. Todos os direitos, inclusive de tradução, são reservados. É permitido citar parte de artigos sem autorização prévia desde que seja identificada a fonte. A reprodução total de artigos é proibida. Os artigos só devem ser usados para uso pessoal e nãocomercial. Em caso de dúvidas, consulte a redação: redacao@rae.com.br.

A RAE-eletrônica é a revista on-line da FGV-EAESP, totalmente aberta e criada com o objetivo de agilizar a veiculação de trabalhos inéditos. Lançada em janeiro de 2002, com perfil acadêmico, é dedicada a professores, pesquisadores e estudantes. Para mais informações consulte o site www.rae.com.br/eletronica.

RAE-eletrônica

ISSN 1676-5648

(C)2002 Editora: Fundação Getulio Vargas - Escola de Administração de Empresas de São Paulo.

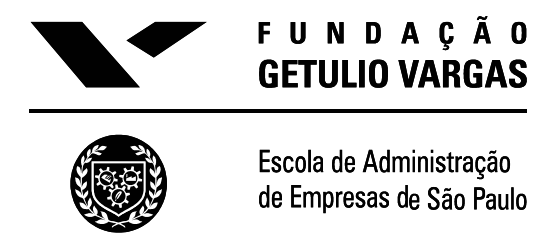




\title{
Criação de Indicadores Estratégicos para o Instituto de Pesquisas Tecnológicas do Estado de São PAULO S.A. - IPT
}

\author{
Edgar Bertini Ruas \\ Graduado em Administração Pública pela FGV-EAESP e Graduando em Engenharia Elétrica pela \\ $\mathrm{POLI} / \mathrm{USP}$ \\ E-mail: edgar.ruas@poli.usp.br
}

Endereço: Rua Rodolfo Belz 155 - Vila Sonia - São Paulo - SP, 05639-010

Interesses de pesquisa: Planejamento Estratégico, Indicadores, Balanced Scorecard e Gestão da Tecnologia

\section{RESUMO}

Este trabalho tem como objetivo a criação de um conjunto de indicadores estratégicos para o Instituto de Pesquisas Tecnológicas do Estado de São Paulo (IPT). Tendo como referencial teórico a metodologia do Balanced Scorecard (BSC), são apresentados 12 indicadores para a Instituição, divididos em quatro perspectivas. São elas: Sociedade, Financeira, Capacitação e Processos. No entanto, devido ao fato do IPT ser uma instituição pública, algumas adaptações foram feitas em relação à metodologia original do $\mathrm{BSC}$, focada essencialmente em empresas privadas. Como guia para a identificação destes indicadores, foi utilizado o Plano Diretor do IPT para 2002, documento que contém as diretrizes estratégicas e linhas de ação para as atividades do Instituto.

\begin{abstract}
This paper intends to create a group of strategic indicators for the Institute for Technological Research (IPT). Following the Balanced Scorecard (BSC) methodology, twelve indicators are presented for the Institution, divided in four perspectives: Society, Financial, Capacitation and Process. Being the Institute a non-profitable state owned company, some considerations were made concerning the original BSC methodology, focused mainly in profitable private enterprises. The Master Plan of IPT for 2002, where the strategies and activities of the Institute are listed, was used as a guide for the identification of the indicators.
\end{abstract}

\section{Palavras-Chave}

Indicadores; Balanced Scorecard; Planejamento Estratégico; Institutos de Pesquisa; Adm. Pública.

\section{KEY WORDS}

Indicators; Balanced Scorecard; Strategic Planning; Research Institutes; Public Administration. 


\section{INTRODUÇÃO}

Vamos nos transportar de volta ao século XIX, mais precisamente para o ano de 1812. Napoleão resolve invadir a Rússia, juntando um exército nunca antes visto: 600 mil homens. As informações da época diziam que o exército russo contava "apenas" com 350.000 homens. Napoleão possuía o melhor equipamento, os melhores generais. Apesar da desconfiança de seus generais na campanha, a vitória parecia óbvia. E vitórias não tardaram a acontecer: Smolensk, Valutino, Borodino, Moscou... Mas todos conhecem o fim desta história: mais de dois terços do exército francês pereceu, grande parte devido ao frio e a falta de suprimentos, em uma corrida desesperada de volta à pátria mãe.

E o que queremos mostrar com isso? Um aspecto em particular: a relação da estratégia com os indicadores. Napoleão sem dúvida era um dos maiores estrategistas que já viveram. No entanto, obcecado em atingir um objetivo que considerava possível, embalado por sua capacitação e nos indicadores amplamente favoráveis aos franceses, acabou cavando sua própria cova. A primeira vista, os indicadores analisados (vitórias, áreas ocupadas, canhões capturados) poderiam mostrar que a guerra estava quase ganha. No entanto, apesar de todos os indicadores mostrarem a superioridade dos franceses, por que ela não foi comprovada?

Este singelo exemplo nos mostra o cuidado que devemos ter ao escolhermos e confiarmos excessivamente nos indicadores. Eles não devem ser mais que medidores da eficácia ou não de nossas estratégias, mostrar se estamos atingindo nossos objetivos.

E escolher os indicadores adequados para que o IPT possa acompanhar o desenrolar de suas estratégias é o objetivo deste trabalho. Tendo como referência o Balanced Scorecard (usaremos a partir de agora a sigla BSC), será proposto um conjunto de indicadores que traduz a estratégia do IPT em quatro perspectivas.

Este seria o principal objetivo deste trabalho, visto a necessidade imediata do Instituto em possuir um banco de indicadores que norteiem suas atividades. Porém, seria o primeiro passo no sentido de uma mudança na cultura gerencial, tendo como objetivo uma implantação total do BSC.

E por que escolher BSC como base para este trabalho de criação de indicadores? Justamente por entender que o BSC não é um simples guia para a criação de indicadores, mas sim toda uma nova filosofia gerencial. Como explicado no capítulo seguinte, o BSC é uma ferramenta poderosa para tornar os rumos estabelecidos mais transparentes e palpáveis para todos os funcionários e, por que não, a toda sociedade.

\section{1) BALANCEd SCORECARd - UMa Nova Abordagem PARA A Administração PúbliCa}

Nesta seção, apresentaremos o sistema de gestão originado nos trabalhos de KAPLAN \& NORTON (1993), conhecido como Balanced Scorecard. Iremos definir o que é estratégia e missão, para assegurarmos que estes conceitos, possibilitando diversas interpretações, tenham para nós o mesmo sentido. Uma vez estabelecido um denominador comum nestes conceitos, fundamentais para este estudo, vamos introduzir o que propriamente vem a ser o BSC. 


\section{1) O Que Entendemos Por Estratégia}

Todas as organizações sejam elas públicas ou privadas, possuem uma missão, visão e algum tipo de estratégia, buscando atingir suas missões. Mas, antes de discutirmos como atingiremos nossa missão, vamos definir o que vem a ser propriamente a missão.

A missão de uma empresa, segundo COLLINS (1998) citado por SCHWARZ (2000, p. 2), é a "contribuição mais duradoura e expressiva e reflete o caráter permanente de uma organização". Ou seja, entendemos que a missão de qualquer organização é o seu propósito de existência, seu escopo operacional e objetivos gerais. A definição da missão responde a algumas perguntas básicas sobre a organização, como por exemplo, quem são nossos clientes, qual o nosso negócio, o que nossos clientes valorizam.

Uma vez definida a missão e objetivos da organização, surge a seguinte questão: como as atingiremos? Para tanto, precisamos definir a nossa estratégia, que segundo WRIGHT, PRINGLE \& KROLL (1992, p. 3) significa "planos da alta administração para atingir resultados consistentes com as missões e objetivos da organização".

Para completarmos a definição de estratégia, falta definirmos o que vem a ser seu aspecto tático. Isto fica mais claro quando temos em mente a definição de CLAUSEWITZ (1984), um teórico militar prussiano da época de Napoleão, sobre estratégia e tática: “... táticas... (envolvem) o uso de forças armadas na batalha, estratégia (é) o uso de batalhas para o uso na guerra"(CLAUSEWITZ, 1984, p. 128). Trazendo para o ambiente organizacional, as batalhas são os projetos ou ações executadas pela organização, tendo em vista a estratégia, que por sua vez está atrelada à missão da organização.

\section{2) O BALANCED SCORECARD}

Uma vez definidas o que vêm a ser a estratégia, a missão e a visão de uma organização, passemos, então, para a tarefa de torná-las reais. E o BSC é a ferramenta escolhida para tal fim.

Segundo estudo realizado pela consultoria Symnetics Business Transformation com 30 empresas de médio e grande porte do Brasil em 1999, menos de 10\% das estratégias são eficientemente formuladas e executadas. Este dado é fruto de inúmeros fatores, mas principalmente devido "a falta de compreensão da relação de interdependência entre planejamento estratégico e gestão estratégica", segundo SCHWARZ (2000, p. 2). E o BSC é justamente a ponte entre o planejamento estratégico e a gestão estratégica.

Segundo KAPLAN \& NORTON (1997), o BSC consiste em uma metodologia que liga as atividades de curto e longo prazo de uma organização com a visão, a missão e a estratégia, através do estabelecimento de metas mensuráveis, definidas por consenso.

A ligação entre missão, visão e estratégia da organização é realizada através da identificação, em um primeiro momento, das ações a serem realizadas pela organização segundo diretrizes aprovadas pela diretoria. Elas devem estar relacionadas numa cadeia de causa e efeito, tendo como base as quatro perspectivas identificadas por KAPLAN \& NORTON (1997) como essenciais para qualquer 
organização obter um verdadeiro crescimento e sucesso no longo prazo, a saber: financeira, dos clientes, de processos internos e aprendizado e crescimento.

É de vital importância que haja um correlacionamento das ações entre si, tendo em vista estas quatro perspectivas. Por exemplo, digamos que a missão de uma empresa qualquer seja ser a empresa mais lucrativa de determinado setor. Para tal fim, a principal ação identificada seria aumentar os lucros (perspectiva financeira). Porém, para atingi-lo, identificamos a necessidade de aumentar o número de clientes (perspectiva dos clientes). Mas, com um aumento da base de clientes, é preciso melhorar a produtividade dos processos internos (perspectiva de processos internos). E, finalmente, para aumentarmos a produtividade, é necessária uma maior qualificação de nossa mão-de-obra ou de novos equipamentos (perspectiva de aprendizado e crescimento).

As quatro perspectivas levantadas são uma alternativa ao modelo até então vigente nas organizações de acompanhamento das ações, essencialmente contemplando a perspectiva financeira. Segundo KAPLAN \& NORTON (1996), o BSC é um complemento à medida financeira, suprindo sua deficiência em monitorar os "ativos intangíveis" essenciais para o crescimento futuro. Podemos visualizar estas relações na figura 2-1 "Traduzindo Missão e Estratégia" a seguir: 


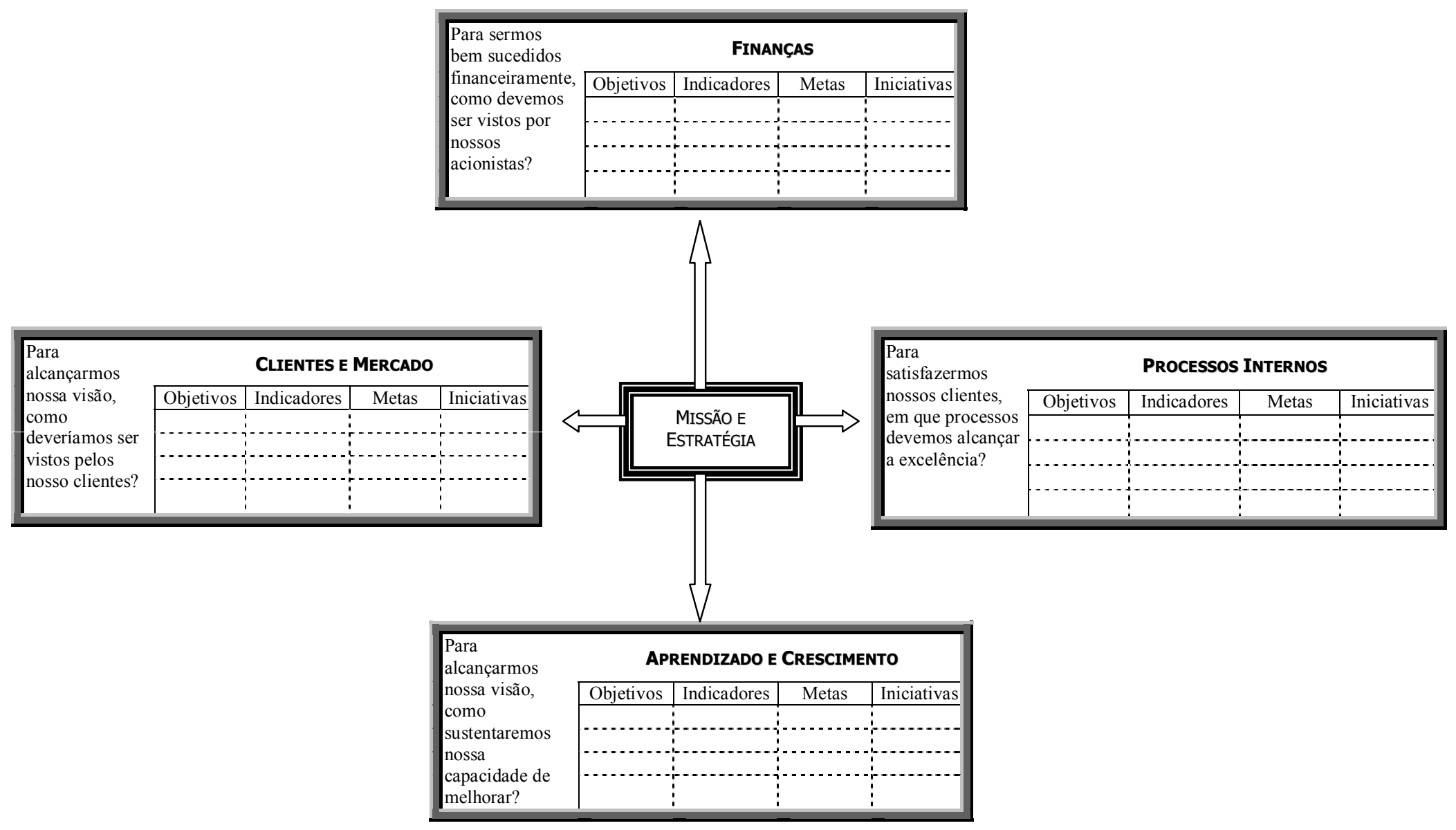

Figura 2-1 "Traduzindo Missão e Estratégia" Fonte: KAPLAN, 1996 
Vamos então agora conhecer um pouco melhor estas quatro perspectivas apresentadas, para uma melhor compreensão da filosofia do BSC, uma vez que esta pautada sobre esta visão "holística" da organização.

\subsection{1) Perspectiva Financeira}

A perspectiva financeira, segundo KAPLAN \& NORTON (1997), seria a síntese das diversas ações tomadas pela organização traduzida na forma econômica. Ou seja, indica se o desempenho financeiro esperado está sendo atingido. No limite, o desempenho financeiro é o objetivo final de todas as outras perspectivas.

No entanto, esta perspectiva possui interpretações diferentes para o setor público e privado. Enquanto, na pior das hipóteses, no setor privado a busca por lucros (ou um maior retorno para o investidor) norteia as ações de longo prazo, já que o ambiente em que estão inseridos é altamente competitivo. E no setor público isto não ocorre. A perspectiva financeira é vista muito mais como um fator restritivo, por exemplo, um orçamento fixo, do que como um objetivo ou um fim. O sucesso de uma organização pública deve ser auferido muito mais em como ela supre eficientemente, eficazmente e efetivamente as necessidades de seus participantes. Portanto, para o setor público, especialmente para institutos de pesquisa, a perspectiva financeira deve enfatizar eficiência na gestão de custos, ou seja, fornecer o máximo valor para a sociedade com o mínimo de custos (MARCOVITCH, 1979).

\subsection{2) Perspectiva do Cliente}

A perspectiva dos clientes consiste primeiramente numa identificação dos segmentos de clientes e mercados onde a organização compete ou presta serviços. Então, mede-se a capacidade da organização de prover produtos e serviços de qualidade, a eficiência de sua entrega e, no final, a satisfação dos consumidores.

É essencial a identificação das necessidades e expectativas dos clientes com relação à organização, justamente para haver um alinhamento da estratégia de negócio. Para instituições privadas, a satisfação dos clientes e sua fidelização seriam a causa primária da obtenção de bons resultados financeiros, seu principal objetivo. No entanto, para instituições públicas, este seria o principal objetivo. Os clientes e a sociedade em geral são os principais interessados e a razão de ser do setor público, portanto devem ser os balizadores de toda e qualquer ação. A responsabilidade para com a sociedade é muito maior em empresas públicas.

\subsection{3) Perspectiva dos Processos Internos}

A perspectiva dos processos internos resulta da identificação, por parte dos executivos, dos processos críticos que levam ao sucesso financeiro e à satisfação dos clientes. Ao contrário das formas tradicionais de gestão, onde o foco é basicamente monitorar e melhorar os processos existentes, o BSC também dedica atenção à identificação de novos processos que podem trazer a satisfação aos clientes. Ou seja, a perspectiva dos processos internos é o meio pelo qual as expectativas de resultados por parte dos clientes são atingidas. 
Para atingirmos as expectativas dos clientes devemos olhar para toda a cadeia de valor das operações internas. A cadeia pode ser dividida em três fases: inovação, onde são detectadas e analisadas as necessidades dos clientes, desenvolvendo-se então novos produtos ou serviços; operações, onde é gerado a prestação do serviço ou o produto; e serviços de pós-venda, onde é realizada toda a assistência ao usurário do serviço ou proprietário do produto.

\subsection{4) Perspectiva de Aprendizado e Crescimento}

Finalmente, a quarta perspectiva, aprendizado e crescimento, trata sobre a qualidade dos sistemas de informação, a capacitação dos funcionários, alinhamento organizacional, enfim, o patrimônio humano e material. A consumação dos objetivos estabelecidos nas perspectivas financeira, de clientes e processos internos só ocorrerá se a infra-estrutura necessária estiver pronta e preparada para o seu cumprimento. Somente se as pessoas estiverem motivadas, treinadas e com informações disponíveis em tempo suficiente nossa estratégia obterá sucesso.

Esta perspectiva adquire especial relevância no setor público hoje em dia, com a atual reforma do Estado. Por atravessar toda uma fase de reciclagem em suas atribuições, assumindo novas responsabilidades e deveres, uma nova capacitação é requerida por parte de seus funcionários, bem como uma completa reformulação de seus equipamentos.

Sintetizando, “... o BSC traduz visão e estratégia em objetivos e medidas através de um conjunto equilibrado de medidas” (KAPLAN \& NORTON, 1997, p.29). Mas ainda nos falta entendermos como quantificar nossas perspectivas, que é o que veremos a seguir.

\subsection{5) Características dos Indicadores}

A maneira de quantificar em metas mensuráveis nossa estratégia, nos pautando pelas quatro perspectivas apresentadas, ocorre por meio de um conjunto de indicadores-chave de desempenho. No entanto, estes indicadores não são um simples instrumento de controle das ações a serem tomadas. Eles devem ser estabelecidos de maneira a deixar clara a ligação entre as ações a serem implementadas e a estratégia do negócio, além de monitorarem o andamento da estratégia. Eles servem essencialmente “... para articular a estratégia da empresa, para comunicar esta estratégia e para ajudar a alinhar iniciativas individuais, organizacionais e interdepartamentais, com a finalidade de alcançar uma meta comum" (KAPLAN \& NORTON, 1997, p. 25).

Vale ressaltar que estes indicadores devem ser separados e escolhidos de acordo com as seguintes características: podem ser medidas de resultados, que não passam de indicadores de ocorrência (lagging indicators), refletindo se as grandes estratégias e os resultados de curto prazo foram atingidos; podem ser também medidas de vetores de crescimento (leading indicators), ou seja, são indicadores de tendência, visando identificar oportunidades ou ameaças para a empresa na sua busca pela criação de valor. Em todas as perspectivas, deve haver um equilíbrio entre estes dois tipos de indicadores, além da clara ligação com as ações estratégicas. Caso os indicadores de ocorrência sejam negligenciados, corre-se o risco da organização se perder em programas de melhoria localizados que não geram valor final. Por outro lado, se superestimados, corre-se o risco de surgirem dúvidas quanto à forma de se atingir os resultados esperados. 
Vamos agora mostrar as etapas necessárias para combinar o planejamento estratégico e o BSC como ferramenta de gestão da estratégia.

\section{3) IMPLEMENTANDO O BSC}

Como já vimos anteriormente, o BSC é uma ferramenta para a implementação e gestão da estratégia. Portanto, o BSC é uma etapa processo de planejamento estratégico. Segundo SCHWARZ (2000), um framework tradicional de planejamento estratégico incorporando o BSC contempla três grandes fases distintas, a saber:

planejamento estratégico, onde são definidas as missões, visão de futuro, onde a empresa quer estar no longo prazo, a analise de pontos fortes, fracos, oportunidades, ameaças à organização, que irão subsidiar a formulação da estratégia da organização;

estratégia em ação, onde o BSC é utilizado para traduzir a estratégia em objetivos, indicadores, metas e planos de ação;

monitoramento, onde a estratégia é analisada e revisada através do BSC.

Estas etapas podem ser vistas com maiores detalhes na figura 2-2, "Etapas do Planejamento Estratégico". 


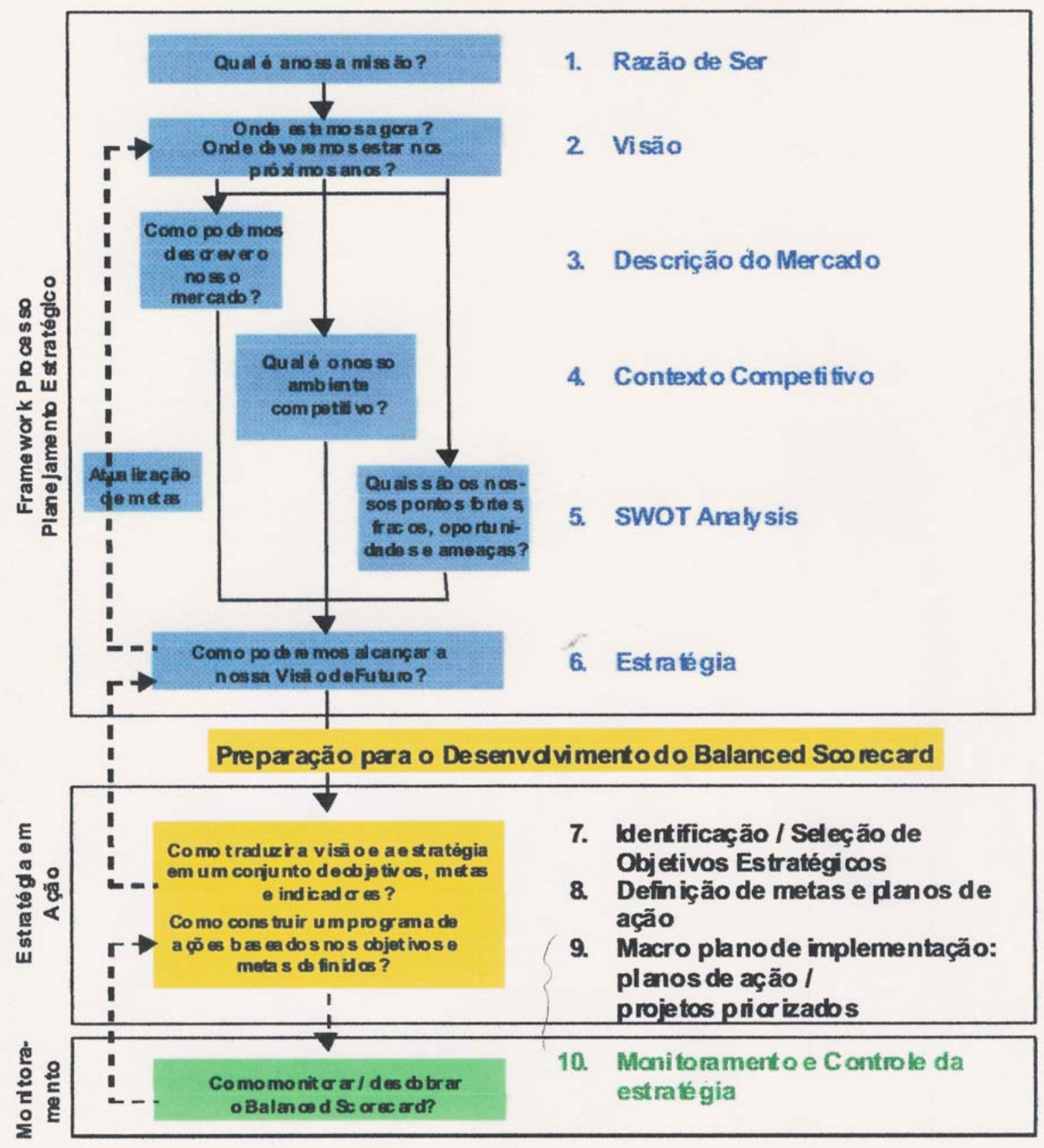

Fig. 2-2 - Etapas do Planejamento Estratégico

Fonte: SCHWARZ, 2000, p. 3

Uma vez definida a estratégia da organização, SCHWARZ (2000) identificou outras quatro fases necessárias para haver uma tradução desta estratégia para indicadores chave de desempenho, além da análise e controle da própria estratégia, descritos a seguir.

> Análise e compreensão da estratégia da organização: esta fase consiste, além da analise e compreensão da visão e dos direcionadores de negócio da organização, avaliar a coerência das 
diretrizes estratégicas com os drivers de negócio, para assegurar que não existem falhas no processo de planejamento estratégico, o que pode comprometer a escolha de objetivos e indicadores.

$>\quad$ Inter-relacionamentos de objetivos estratégicos: deve-se aqui alocar os objetivos estratégicos nas quatro dimensões do BSC, correlacionando-os entre si.

$>$ Definição de indicadores chave de desempenho: nesta fase são definidos os indicadores que medem diretamente cada objetivo estratégico, indicadores complementares a estes e, se possível, indicadores que correlacionam as diretrizes entre si. Segundo KAPLAN \& NORTON (1993), o número de indicadores não deve ultrapassar 20. Feito isso, deve-se então definir metas, planos de ação e os responsáveis para tal.

$>\quad$ Monitoramento e controle da estratégia: finalmente, busca-se nesta etapa identificar o cumprimento ou não das metas, a validade dos indicadores, através de reuniões periódicas de cúpula.

\section{2) A IMPLANTAÇÃo do BSC NO IPT}

Esta parte contém a proposta da criação de um banco de indicadores para o IPT, como primeiro passo para a implementação do BSC. Para tanto, mostraremos como é realizado o processo de planejamento estratégico, apresentando a estratégia definida pelo Instituto para o ano base de 2002.

\section{1) O PlaneJamento Estratégico do IPT}

Antes de entrarmos em maiores detalhes sobre o processo do planejamento estratégico, é conveniente explicitarmos a missão do Instituto, conforme escrita em seu Estatuto Social, capitulo 3, do ano 1984, Artigo $3^{\circ}$ :

"Artigo $3^{0}$ - A Sociedade (IPT) tem por objetivo atender a demanda de ciência e tecnologia dos setores público e privado, no seu campo de atuação, bem como contribuir para o desenvolvimento do conhecimento científico e tecnológico, cabendo-lhe entre outras atividades:

I - executar projetos de pesquisa e desenvolvimento científico e tecnológicos;

II - dar apoio técnico ao desenvolvimento da engenharia e indústria;

III - formar e desenvolver equipes de pesquisa, capazes de contribuir para o equacionamento e a solução de problemas de tecnologia industrial do Estado e do País;

IV - colaborar em programas de especialização de técnicos diplomados pela Universidade de São Paulo e por outras Instituições de ensino superior, em áreas de interesse da ciência e da tecnologia;"

Todo o processo de planejamento estratégico do IPT está pautado neste artigo. Apesar da idade do artigo, ele permanece atualizado, oferecendo uma base satisfatória para o Instituto nortear suas estratégias. Porém, o que tem mudado, ao longo dos anos, são as diretrizes estratégicas derivadas do estatuto.

As diretrizes estratégicas são estabelecidas a partir da interpretação do estatuto pela diretoria executiva, juntamente com o Conselho de orientação do IPT, levando-se em conta a situação atual de todo o Instituto e do ambiente externo a ele. A cada ano, são realizadas reuniões de cúpula onde são definidas estas diretrizes. Como conseqüência, é elaborado no final do ano, juntamente com as unidades técnicas, um Plano Diretor para o ano seguinte. 
O plano estabelece todas as ações a serem seguidas, não necessariamente novas, coerentes com as diretrizes estratégicas previamente estabelecidas.

\subsection{1) O Plano Diretor 2002 - Estratégias para o IPT}

Prover apoio tecnológico ao setor produtivo, apoiar políticas públicas e aprimorar e disponibilizar seu acervo tecnológico. Estas foram as missões essenciais do IPT que a diretoria executiva procurou atender ao estabelecer as diretrizes estratégicas para o exercício de 2002 . As diretrizes estratégicas então estabelecidas pela diretoria foram quatro, a saber:

$>$ aumentar as atividades de Pesquisa, Desenvolvimento e Inovação;

$>$ aumentar a participação em redes de excelência tecnológica, tanto internas quanto externas;

$>$ aumentar em $5 \%$ as receitas reais;

$>$ renovar e valorizar os funcionários e colaboradores da instituição.

Com as diretrizes prontas, foram levantadas as principais ações a serem desenvolvidas pelas diferentes áreas técnicas e de apoio do IPT. As ações se encontram inseridas em dois macro ambientes, internos ou externos ao Instituto, e em linhas de ação, que por sua vez têm um objetivo comum, pertencendo ao ambiente externo ou interno.

Para uma melhor compreensão da relação de causalidade entre missões, diretrizes e linhas de ação, veja-se a fig. 2-3 "Missões e Diretrizes" na página seguinte. 


\section{MISSÕES - DIRETRIZES - LINHAS DE AÇÃO}

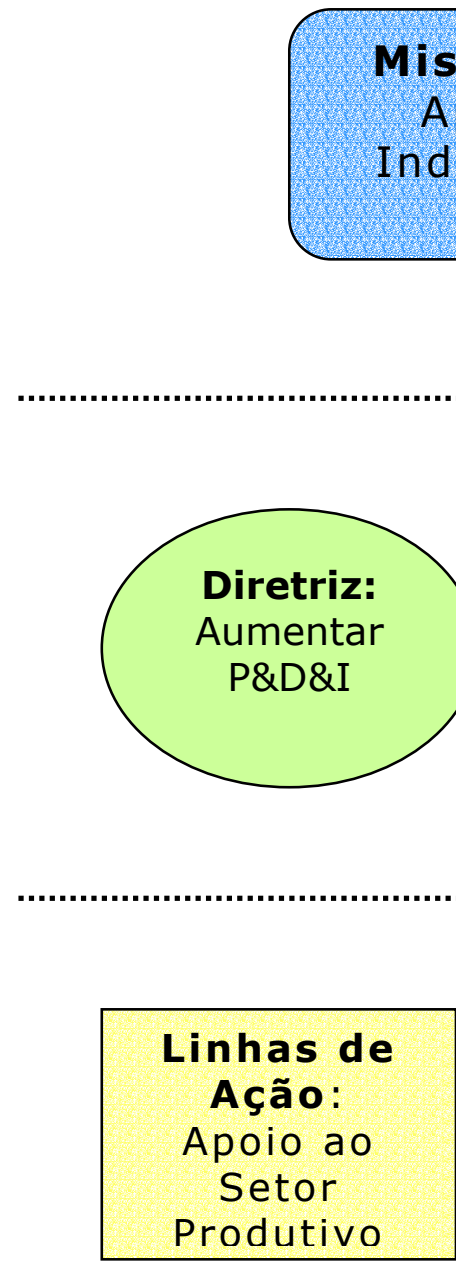

Missão 1:

Apoiar

ndústrias
Missão 2:

Apoiar

Políticas

Públicas
Missão 3 :

Acervo

Tecnológico

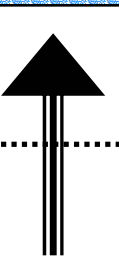

$\|$
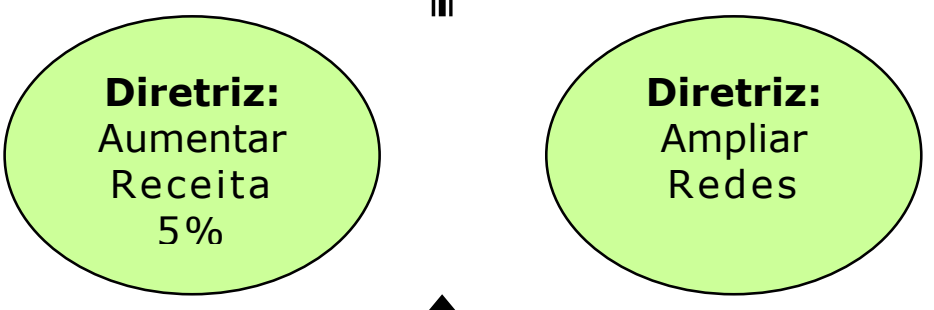

\section{Diretriz:}

Renovar e

Valorizar

$\mathrm{RH}$

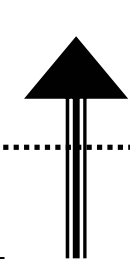

Linhas de
Ação:
Apoio a
Políticas
Públicas
Linhas de
Ação:
Força de
Trabalho
01 Linha; 04

\section{Linhas de ação: \\ Sistema de Gestão \\ 01 Linha; 06}

Figura 2-3 - "Missões e Diretrizes"

Fonte: Plano Diretor 2002 


\section{2) A Proposta}

Os indicadores sugeridos neste tópico são essencialmente estratégicos, ou seja, procuram demonstrar para a alta diretoria se a estratégia estabelecida está surtindo efeito. Estes não são indicadores táticos ou operacionais, que deverão ser escolhidos, caso seja necessário, dentro de cada unidade técnica do Instituto, visto a diversidade de atuação das mesmas. No entanto, os indicadores propostos servem de guia para as unidades estabelecerem seus próprios indicadores, uma vez que eles são a tradução da estratégia do Instituto como um todo.

As missões básicas do IPT, além das diretrizes estratégicas definidas pela diretoria executiva do Instituto, serão o ponto de partida para nosso Scorecard. Como já foi descrito na seção Implementando o BSC, o próximo passo seria a correlação dos objetivos estratégicos com as quatro perspectivas do BSC. Faremos aqui, no entanto, duas observações.

A primeira delas diz respeito à identificação destes objetivos estratégicos. Como a diretoria executiva, ao elaborar o plano diretor de 2002, não tinha em mente a implementação do BSC, estes objetivos estratégicos não foram explicitados. $\mathrm{O}$ ideal seria um novo planejamento, mas como isso não é possível, iremos utilizar os objetivos implícitos no documento original do Plano Diretor 2002 e as diretrizes estratégicas, além das informações contidas no capítulo 1. A definição das metas para os objetivo estratégicos devem ser estabelecidas pela diretoria executiva, preferencialmente por consenso. Alguns dos objetivos apresentados são genéricos, possibilitando diversas interpretações. Por exemplo, profissionais altamente qualificados. O que se entende por este objetivo? Daí a necessidade de se obter consenso em metas que guiarão o desenvolvimento da estratégia. Porém, este é um trabalho para a diretoria executiva, saindo do escopo deste trabalho.

A segunda observação diz respeito à nomenclatura que daremos às quatro perspectivas do BSC. Por se tratar de uma empresa pública prestadora de serviços não usuais, como pesquisa e desenvolvimento, com características particulares, optamos por nomear algumas dimensões do BSC com outros nomes, apesar de refletirem, essencialmente, a mesma coisa. Utilizaremos, ao invés de perspectiva dos clientes, perspectiva da sociedade. Isto para deixar claro para os stakeholders que o principal cliente do IPT é a sociedade como um todo, não simplesmente o requisitante de algum serviço, especialmente metrologia, apesar de possuir um cunho diferente. Ao invés de perspectiva de aprendizagem e crescimento, utilizaremos perspectiva de capacitação. Sendo um instituto de pesquisa, cuja principal missão "é a busca por conhecimento e a prestação de serviços para a solução de problemas prioritários da comunidade", segundo MARCOVITCH (1979, p. 69), a capacitação de seus funcionários para atingir tal fim é primordial, uma vez que eles são a massa crítica de qualquer instituto. As outras perspectivas, financeira e de processo internos, continuam com estes nomes.

Vejamos na figura 2-4 "Objetivos Estratégicos" como ficarão os objetivos estratégicos alocados nestas quatro perspectivas, seguindo os moldes propostos por KAPLAN \& NORTON (1993): 


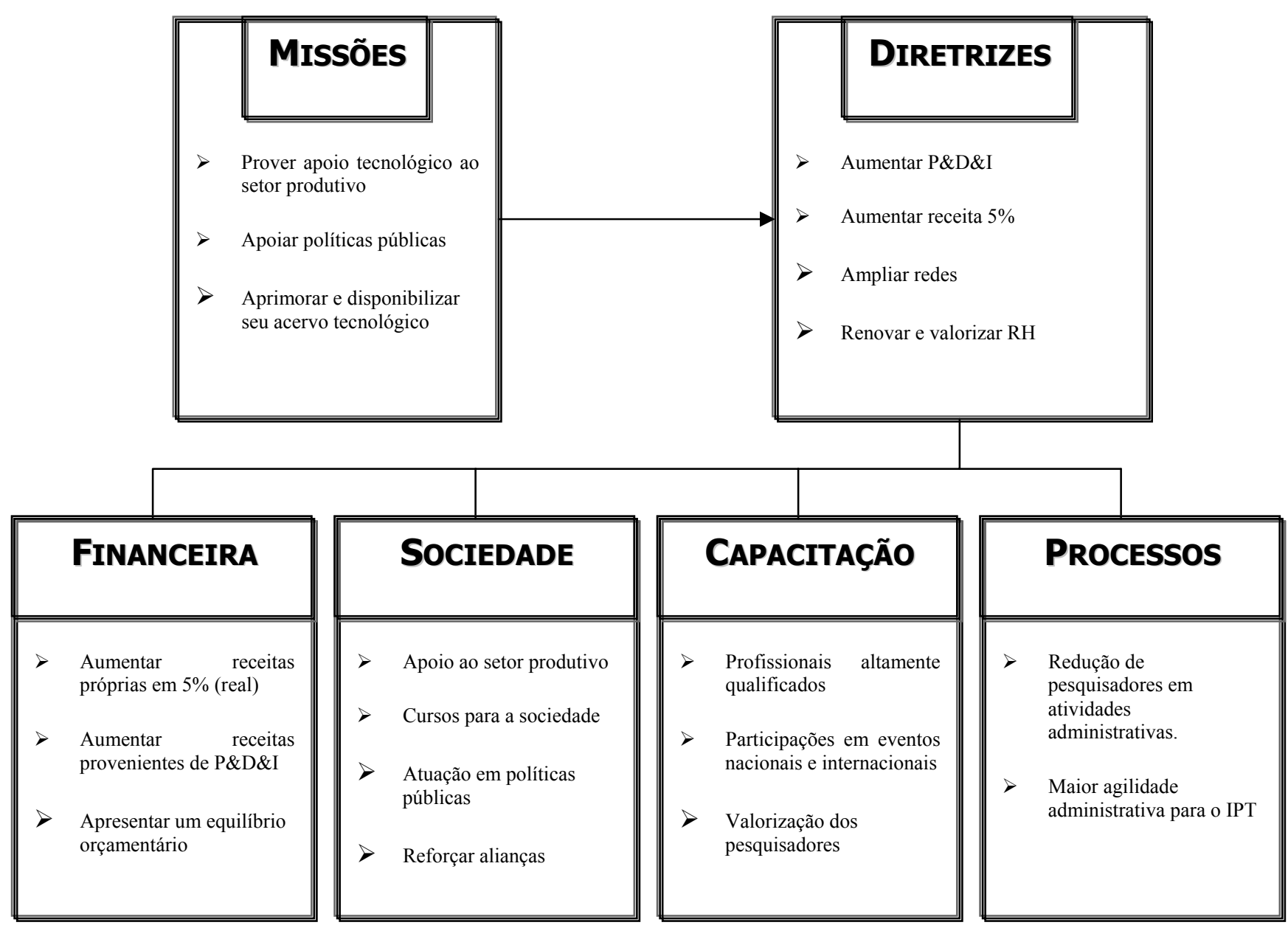

Figura 2-4 - "Objetivos Estratégicos"

Fonte: Baseado em NORTON \& KAPLAN, 1993, P. 135

\subsection{1) Indicadores para a Perspectiva Sociedade}

Este é o verdadeiro objetivo do Instituto, gerar bem estar à sociedade. Os indicadores de tendência escolhidos são:

$>$ pesquisa de Satisfação do Cliente realizada pelo SAC. Esta pesquisa já é realizada com os clientes de alguns laboratórios que prestam serviços de metrologia, atribuindo uma nota de 1 a 5 para diversos itens, como prazo, atendimento, solução proposta entre outros;

$>\quad$ índice de apoio às políticas públicas, definido como o valor dos contratos de apoio a políticas públicas sobre valor total dos contratos. Estes dados são facilmente encontrados na base de dados disponíveis na coordenadoria econômica financeira. Além disso, nos mostra o quanto do Instituto está atuando no auxílio às políticas públicas;

$>\quad$ índice de participação em redes, definido como valor dos contratos relativos a fundos setoriais sobre valor total dos contratos. Os fundos setoriais foram criados pelo governo federal para desenvolver áreas estratégicas, estimulando a formação de redes de excelência em áreas como recursos hídricos, petróleo entre outros. 
Para os indicadores de desempenho, sugerimos o seguinte:

$>\quad$ índice de difusão de conhecimento, definido como o valor alocado em cursos para a sociedade (mestrado profissional, cursos de especialização) sobre despesas totais;

$>\quad$ visitas ao site do IPT durante as semanas;

$>$ participações na elaboração de normas técnicas, definida como número de participações na elaboração de normas técnicas sobre número de pesquisadores. Com isso, temos a participação do IPT na elaboração de normas técnicas para a sociedade.

\subsection{2) Indicadores Financeiros}

Como foi dito na seção Perspectiva Financeira, este conjunto de indicadores possuem características mais restritivas ao bom andamento do Instituto. Portanto, não são um fim pra o IPT e sim um meio para se atingir melhor suas missões.

Os indicadores de tendência escolhidos para esta perspectiva são:

$>\quad$ índice de receita de $\mathrm{P} \& \mathrm{D}$, definida como receitas em projetos de P\&D sobre receitas totais. Este indicador nos mostra quanto de nossa receita total vem de projetos de pesquisa e desenvolvimento. Pelas características peculiares da atividade de P\&D, deve-se tomar cuidado para aumentar a porcentagem sem aumentar consideravelmente as despesas, já que P\&D é uma atividade de longo prazo. Um caminho seria aumentar ou aproveitar melhor a capacitação dos recursos humanos;

$>$ crescimento da receita financeira, definida como receitas próprias captadas no período atual sobre receitas próprias captadas no período anterior, ou seja, aquelas que não dependem de dotação orçamentária.

Os indicadores de desempenho escolhidos são:

$>\quad$ captações de recursos próprios, definido como receitas próprias sobre despesas totais. Com este indicador, mede-se o quanto estamos atendendo a demandas que, apesar do setor público participar, não possuem um cunho de apoio às políticas públicas, já que estes são basicamente subsidiados. Além disso, nos mostra a tendência das dotações orçamentárias fornecidas pelo governo;

$>$ resultado operacional, definido como receita total menos despesa total. A combinação deste indicador com o anterior nos mostra se as dotações orçamentárias ou as receitas próprias são insuficientes, dentro do planejado.

\subsection{3) Indicadores de Processos Internos}

O escopo destes indicadores são os processos relativos às atividades fim e de apoio providas pelo Instituto. Os indicadores de tendência escolhidos são os seguintes:

$>\quad$ índice de aprovações de propostas, definida como propostas aprovadas sobre propostas encaminhadas. Um aumento da qualidade da elaboração da proposta, juntamente com uma maior qualidade da proposta em si, são fatores por detrás deste indicador.

Os indicadores de tendência escolhidos são os seguintes:

$>\quad$ tempo de pesquisadores dedicados a atividades administrativas, definido como número de horas de pesquisadores alocadas em trabalhos administrativos sobre a jornada de trabalho total de 
pesquisadores. Os pesquisadores têm como objetivo realizarem trabalhos de campo. Funções administrativas são de responsabilidade de pessoal contratado especialmente para este fim;

$>\quad$ índice de aprovação de orçamentos, definido como orçamentos apresentados ao cliente sobre orçamentos aprovados. Mostra a qualidade dos trabalhos produzidos pelos pesquisadores ou administradores do IPT.

\subsection{4) Indicadores de Capacitação}

Segundo as palavras do atual presidente do IPT, superintendente do Instituto no período de 1964 a 1984, Alberto Pereira de Castro, "a Instituição não tem competência técnica própria, a competência técnica existente é propriedade particular do técnico que a possui" IPT (1999). Isto nos mostra a importância desta perspectiva. Os indicadores de tendência escolhidos foram:

$>$ número de pesquisadores doutores sobre número de pesquisadores;

$>$ índice de investimento em capacitação e treinamento, definida como despesas alocadas em treinamento e capacitação dos funcionários sobre despesa total. Isto retrata o quanto o IPT investe em seus funcionários.

Os indicadores de desempenho escolhidos foram os seguintes:

$>$ participações no meio externo, definido como número de publicações externas sobre número de pesquisadores total;

$>$ participações em cursos externos, definido como número de horas de pesquisadores em cursos externos sobre a jornada de trabalho total de pesquisadores.

\section{ReSUltados ESPERADOS}

Como já foi visto, o Instituto não possui atualmente um conjunto de indicadores para medir a operacionalização ou não de suas estratégias. Os indicadores sugeridos têm como principal objetivo suprir esta necessidade no curto prazo, auxiliando o acompanhamento das ações. Com isso, a estratégia já definida para o exercício de 2002 passa a ser melhor gerida.

No entanto, pretende-se em médio prazo (talvez já para o próximo ano) uma reciclagem do processo de planejamento estratégico do Instituto, tendo como matriz metodológica o BSC. Os indicadores criados seriam uma espécie de catalisadores deste processo, disseminando uma nova cultura gerencial, direcionando os esforços de planejamento futuros em direção ao BSC, em todo o Instituto.

Só que para este objetivo mais ambicioso tornar-se realidade, é necessário que a diretoria executiva assuma a bandeira do BSC. Além de redefinir o processo de planejamento estratégico do Instituto, pautado agora pelo BSC, é necessário que todas as unidades técnicas e de apoio também tenham consciência e participem deste processo. Mais uma vez cabe à diretoria transmitir o BSC para as unidades técnicas e de apoio, legitimando o processo e tornando-o executável.

Espera-se com a adoção destas medidas suprir a deficiência do Instituto em conduzir e acompanhar o desenrolar de suas estratégias, podendo assim ser um melhor prestador de serviços para a sociedade e valorizar mais o dinheiro (do) público. 


\section{BIBLIOGRAFIA}

CHANDLER Jr, Alfred D. Strategy and Structure. Cambridge, MIT Press, 1990.

CLAUSEWITZ, Carl von. On War. Princeton, Princeton University Press, 1984.

ESTATUTO SOCIAL do Instituto de Pesquisas Tecnológicas de São Paulo S.A. Aprovado em 24/07/87 na $64^{\mathrm{a}}$ reunião extraordinária do Conselho de Orientação e modificada em 31/07/90 na 79 reunião do Conselho de orientação.

KAPLAN, Robert S. \& NORTON, David P. A Estratégia em Ação: Balanced Scorecard. 8 Ed. Rio de Janeiro: Campus. 1997.

KAPLAN, Robert S. \& NORTON, David P. Using the Balanced Scorecard as a Strategic Management System. Harvard Business Review, Boston, v. 74, n. 1, p. 75-85, Jan./Fev. 1996.

KAPLAN, Robert S. \& NORTON, David P. Putting the Balanced Scorecard to Work. Harvard Business Review, Boston, v. 71, n. 5, p. 134-147, Sep./Out. 1993.

MARCOVITCH, Jacques. Eficiência e Eficácia na Instituição de Pesquisa Aplicada. Revista de Administração Pública, Rio de Janeiro, v.79, n01, Jan/Mar, 1979.

PLANO DIRETOR 2002 do Instituto de Pesquisas Tecnológicas do Estado de São Paulo. Consultado em 10/04/02 no endereço http://www.ipt.br/institucional/metas/.

SCHWARZ, Fanny. Management Scorecard: Alinhando Indicadores de Desempenho à Estratégia Empresarial. Symnetics Business Transformation.

WRIGHT, P.; PRINGLE, C. \& KROLL, M. Strategic Management Text and Cases. 1st. Ed. Needham Heights, MA: Allyn and Bacon, 1992. 